\title{
Research on Source-Network Coordination Voltage Control Strategy of Photovoltaic Power Plant Considering the Stability of Inverter Port Voltage
}

\author{
Jinhui $\mathrm{Ma}^{1}$, Haifeng $\mathrm{Ye}^{1}$, Zhi $\mathrm{Li}^{1}$, Pingping Han ${ }^{2}$, Zihao Lin ${ }^{2,}$, and Jianxiong Shi ${ }^{2}$ \\ ${ }^{1}$ State Grid Anhui Electric Power Co., Ltd, Hefei, China \\ ${ }^{2}$ Anhui Provincial Laboratory of New Energy Utilization and Energy Conservation, Hefei University of Technology, Hefei, China
}

\begin{abstract}
At present, the reactive power distribution method considering the reactive power adjustment capacity of the inverter in the photovoltaic (PV) power plant will lead to the output voltage of the inverter exceeding the limit. In particular, the PV inverter adopts the constant reactive power control to support the voltage at point of common coupling (PCC), which has a good effect in the steady-state operation. However, when the system is subject to transient disturbance, the PV inverter cannot flexibly support the voltage level of the system by changing the reactive power output. Therefore, this paper proposes a source-network coordination control strategy aiming at the stability of bus voltage at PCC and inverter port voltage. Firstly, the paper introduced the advantages of constant voltage control of PV inverter. Then, the voltage and reactive power control objectives of the PV Inverter in the PV power plant were calculated by considering the PCC voltage, tie lines, power collection lines, the power of transformers and the voltage loss to realize the voltage and reactive power balance control between the inverters. Finally, an actual PV power plant simulation model was built to analyse the PCC voltage under the two conditions of PV output fluctuation and system fault to verify the effectiveness of the control strategy proposed in this paper. The proposed strategy has engineering application value for the realization of closed-loop voltage control between the power grid and PV power plant and the improvement of the active response ability to the PCC voltage.
\end{abstract}

\section{Introduction}

The large access of random and intermittent distributed PV to power grid makes the operation of the system more complex. The uncertainty of the output will affect the voltage fluctuation of power grid, thus endangering the safe and stable operation of power grid [1]. Therefore, large PV power plant should be equipped with reactive power capacity in accordance with the principle of basic balance in layers and zones, with the ability of automatic reactive power adjustment and voltage control $[2,3]$.

For the control of PCC voltage of the PV power plant, the secondary automatic voltage control (AVC) system issues the reactive voltage command of PCC and distributes the reactive power to the inverters and other reactive sources in the PV power plant. At present, there are three main methods of reactive power distribution in the PV power plant. One is to use the prediction information to switch the capacitor or transformer in advance for coarse adjustment, and then use the inverters and static var generator (SVG) to accurately adjust the voltage [4]. The second is to prioritize SVG, which can suppress the voltage fluctuation caused by the disturbance with the rapidity of SVG, and then replace the reactive power of SVG with the slow response reactive power source such as capacitor and inverters to ensure that SVG has a large reactive power margin $[5,6]$. The third is to arrange inverters first and the capacitor and SVG undertake the shortage [7-9]. The first two methods fail to make full use of the reactive power capacity of the PV inverter, which leads to the large reactive capacity required to be configured in the PV power plant and the poor economy. The third method can make full use of the reactive power of PV inverter. However, since the method of distributing reactive power to the PV inverter is generally to distribute the reactive power command in proportion of the PV power generation capacity or equal power distribution [10], the terminal voltage of the PV inverter at the end of the line may be affected by the transformer and cable lines in the $\mathrm{PV}$ power plant and close to the critical value.

To sum up, the reactive power distribution method considering the reactive power capacity of the inverter in the PV power plant is easy to cause the output voltage of the PV inverter to exceed the limit. In particular, the PV inverter adopts constant reactive power control to support the PCC voltage, which has a good effect in the steady-state operation. However, when the system occurs transient disturbance, the PV inverter cannot flexibly support the voltage level of the system by changing the reactive power output. Based on this, the paper proposes a source-network coordination control strategy aiming at

\footnotetext{
* Corresponding author: 1zh36566@163.com
} 
the stability of bus voltage at PCC and inverter port voltage in the PV power plant. In the second part of the paper, the reactive power and voltage adjustment ability of PV inverter was analysed. The two voltage control modes of constant voltage and constant reactive power were introduced. In the third part, under the constant voltage control mode of the PV inverter, the voltage control objective of the PV inverter in the PV power plant was calculated by comprehensively considering the PCC voltage, tie lines, transformers, power collection lines and the voltage loss to realize the voltage and reactive power balance control between the inverters. In the fourth part, based on DIgSILENT/PowerFactory software platform, the actual PV power plant model was built. The effectiveness of the control strategy proposed in this paper was verified by the analysis of the PCC voltage under the conditions of PV output fluctuation and system fault.

\section{Reactive power and voltage control of PV inverter}

\subsection{Reactive power and voltage adjustment capacity of the inverter}

PV power generation is connected to power grid through the inverter with reactive power adjustment capability, which has the capability of reactive power generation and absorption. The adjustable capacity is limited by the $P-Q$ curve shown as Fig. 1 [11]. It can be seen that the formula between the adjustable reactive power capacity and the inverter capacity of the PV inverter is as follows:

$$
Q_{\mathrm{PV}}^{\mathrm{MAX}}= \pm \sqrt{S_{\mathrm{INV}}^{2}-P_{\mathrm{PV}}^{2}}
$$

In Formula (1): $Q_{\mathrm{PV}}^{\mathrm{MAX}}$ is the reactive power output capacity of PV inverter; $P_{\mathrm{PV}}$ is the active power of PV inverter; $S_{\mathrm{INV}}$ is the capacity of PV inverter, which limits the active and reactive power of PV to a certain range. Under different control modes, the output reactive power of the inverter is dynamically adjustable in the area as Fig. 1.

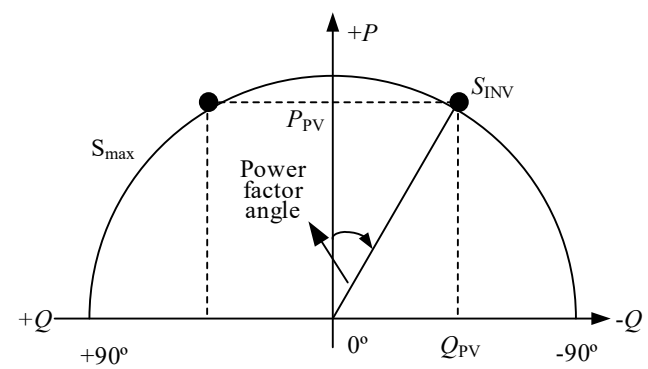

Fig. 1. $P-Q$ curve of $P V$ inverter.
The constant reactive power control mode of the inverter is that the inverter provides constant reactive power support to the system to maintain the stability of the PCC voltage. The required reactive power command is determined according to the upper scheduling plan. When the PV inverter operates in the constant reactive power control mode, the generated reactive power can effectively support the PCC voltage in the steady-state operation [12]. However, due to the incomplete construction of load forecasting system and unreliable forecasting results, distributed PV power plants are vulnerable to the influence of solar irradiance variation, meteorological changes and other factors in the process of power generation, resulting in the randomness and fluctuation of power generation load [13]. When the system occurs transient disturbance, the inverter under constant reactive power control cannot change the reactive power to support the PCC voltage, resulting in system voltage fluctuation. Therefore, the inverter needs to adopt the constant voltage control mode as shown in Fig. 2 instead of the traditional constant reactive power control mode. According to the $Q-U$ characteristics, the inverter can realize the fast tracking of the terminal voltage, and then realize the fast response and stable control of the target voltage and system voltage disturbance.

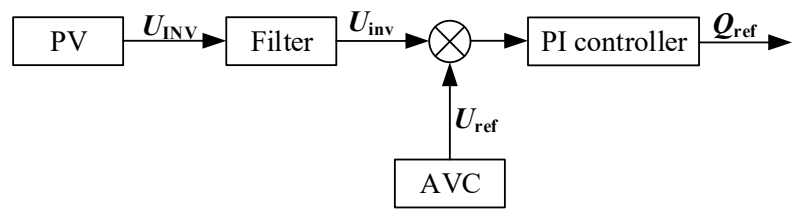

Fig. 2. Constant voltage control block diagram of inverter.

The constant voltage control mode shown as Fig. 2 is to compare the actual port voltage of the inverter $U_{\mathrm{INV}}$ with the reference voltage $U_{\text {ref }}$ and convert the actual voltage into the reactive power reference value $Q_{\text {ref }}$ required by the PV system through the PI closed-loop regulator, so as to make the port voltage track and stabilize near the reference value. The calculation formula is as follows:

$$
Q_{\mathrm{ref}}=\left(K_{\mathrm{p}}+k_{\mathrm{i}} \frac{1}{S}\right)\left(U_{\mathrm{ref}}-U_{\mathrm{inv}}\right)
$$

In Formula (2), $U_{\text {inv }}$ is obtained by filtering $U_{\text {INV. }} K_{\mathrm{p}}$ and $K_{\mathrm{i}}$ are respectively the proportional coefficient and the integral coefficient of PI controller. PI parameters are calculated according to the voltage of PV access point and the static voltage and reactive power difference adjustment characteristics. With constant voltage control mode, the inverter can effectively adjust the reactive power output to stabilize the system voltage according to the real-time output, which makes the PV power plant adapt to the situation of PCC voltage fluctuation during the transient operation.

\section{Source-network coordination voltage control strategy of PV power plant}


The source-network coordination voltage control strategy of PV power plant refers to the redistribution of voltage commands among inverters based on the PCC voltage, tie lines, transformers, power collection lines and the voltage loss, so as to realize the reactive power and voltage balance control between inverters. The closed-loop coordination control between power grid and PV power plant is finally realized.

\subsection{AVC working mode in the PV power plant}

The topological structure of the communication system that the AVC system in the PV power plant relies on is shown as Fig. 3. Based on the graphic communication structure, AVC system collects the parameter data and state variable data of the inverters and lines in the PV power plant, calculates the reactive power optimization according to the received target command, and sends the calculated results to each inverter controller. The inverter completes the fast voltage adjustment and the real-time data is fed back to the control layer by AVC system.

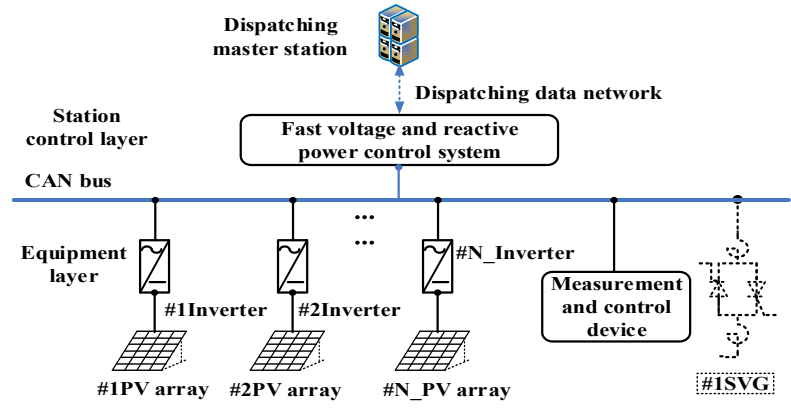

Fig. 3. Communication system topology.

At present, the communication mode of AVC system mainly adopts the channel of combination of serial and network and the communication mechanism mainly adopts polling and triggering mode. The following process is generally about 2-3 minutes: System receiving control command - Analysis and calculation - Target output control - data communication - Controller response - Feedback of data to system [14]. Therefore, the source network coordination voltage control strategy proposed in this paper comprehensively considers the PCC voltage, tie lines, transformers, power collection lines and the voltage loss to determine the voltage control objectives of PV inverters in the PV power plant, so as to realize the active response and rapid support of the PV power plant to the system voltage disturbance.

\subsection{Reactive power and voltage control process}

The equivalent circuit of PV power plant connected to power grid is shown as Fig. 4. In Fig. $4, Z_{1}=R_{1}+\mathrm{j} X_{1}$ is the impedance of the outgoing line of the PV power plant; $Z_{2}=R_{2}+\mathrm{j} X_{2}$ is the impedance of the power collection lines from the bus to each transformer; $Z_{\mathrm{T}}=R_{\mathrm{T}}+\mathrm{j} X_{\mathrm{T}}$ is the impedance of the transformer; $P$ and $Q$ are respectively the active power and reactive power of the system.

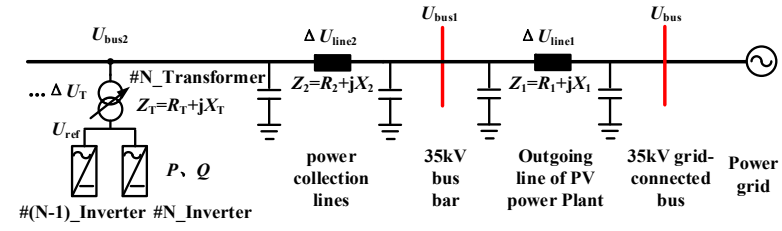

Fig. 4. Equivalent circuit of PV power plant connected to power grid.

Combined with the equivalent circuit diagram, the process of calculating the inverter port voltage and the AVC system control process are as follows:

1) In order to improve the data acquisition rate, data self-acquisition is carried out at the beginning of the transmission line in the PV power plant, including voltage, active power and reactive power.

2) After receiving the target voltage command $U_{\text {bus }}$ from the dispatcher, the validity and scope of the command are checked and recorded.

3) According to impedance parameters, admittance parameters, line length and power flow data of the outgoing line of the PV power plant, the voltage target value $U_{\text {bus1 }}$ of bus bar in the PV power plant is calculated considering voltage loss $\Delta U_{\text {linel }}$ as Formula (3).

$$
\left\{\begin{array}{l}
\Delta U_{\text {linel }}=\frac{P R_{1}+Q X_{1}}{U_{\text {bus }}} \\
U_{\text {busl }}=U_{\text {bus }}+\Delta U_{\text {linel }}
\end{array}\right.
$$

4) Considering the voltage loss $\Delta U_{\text {line2 }}$ of the power collection lines from the bus to each transformer, the target voltage $U_{\text {bus2 }}$ at the output side of each transformer is obtained as Formula (4).

$$
\left\{\begin{array}{l}
\Delta U_{\text {line } 2}=\frac{P R_{2}+Q X_{2}}{U_{\text {bus1 }}} \\
U_{\text {bus } 2}=U_{\text {bus } 1}+\Delta U_{\text {line2 }}
\end{array}\right.
$$

5) According to the voltage loss $\Delta U_{\mathrm{T}}$ and the transformation ratio $K_{\mathrm{T}}$ of the transformer, the target voltage $U_{\text {ref }}$ of inverter port is calculated as Formula (5).

$$
\left\{\begin{array}{l}
\Delta U_{\mathrm{T}}=\frac{P R_{\mathrm{T}}+Q X_{\mathrm{T}}}{U_{\text {bus } 2}} \\
U_{\text {ref }}=\frac{U_{\text {bus } 2}+\Delta U_{\mathrm{T}}}{K_{\mathrm{T}}}
\end{array}\right.
$$

6) The control target is checked and revised to ensure that the target voltage is within the safe voltage range at the inverter outlet.

7) The target voltage is sent to the inverter controller. The inverter completes the fast voltage adjustment and the real-time data of the inverter is fed back to the control system.

In conclusion, the workflow of AVC system can be summarized as Fig. 5. 


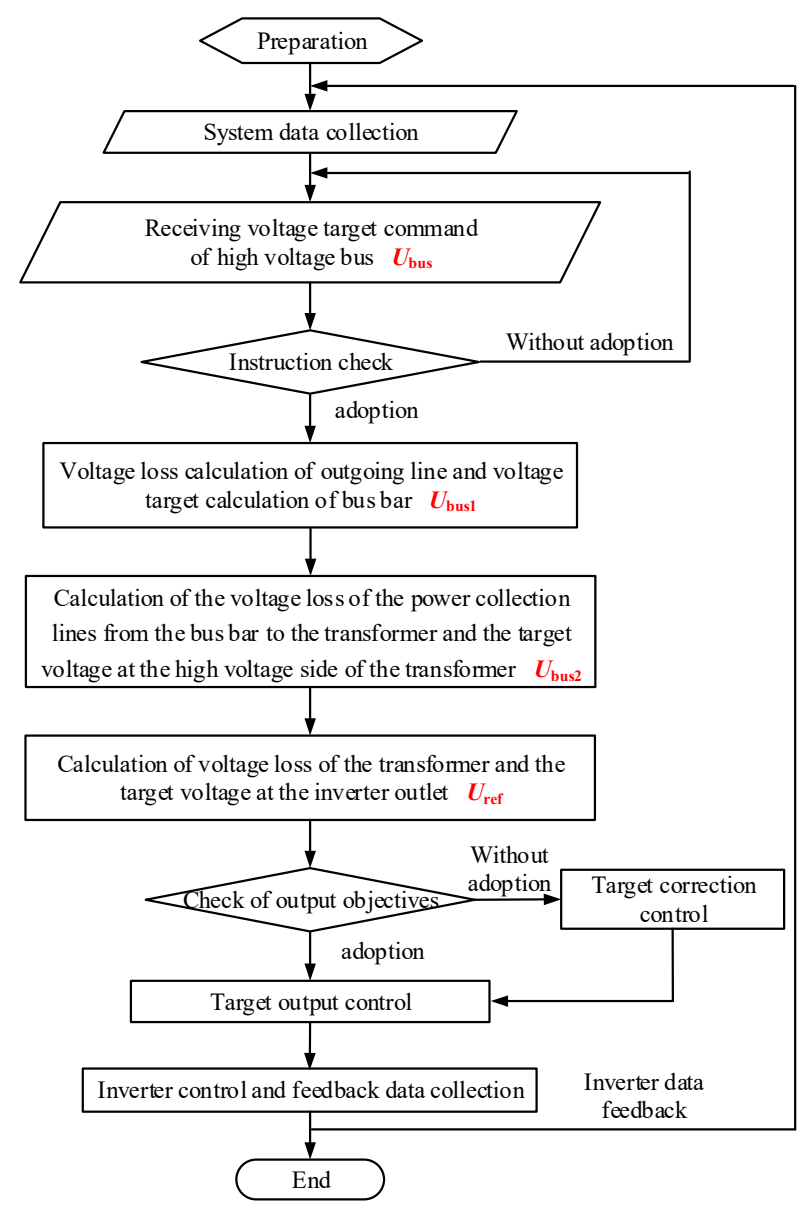

Fig. 5. The workflow of AVC system.

\section{Example verification}

\subsection{Overview of the PV power plant}

The main wiring diagram of an actual PV power plant is shown as Fig. 6. The capacity of the PV power plant is 40MVA. It is equipped with 80 inverters and 40 transformers. One SVG in hot standby state has a capacity of \pm 9 Mvar. The high voltage side of the transformer is $35 \mathrm{kV}$. Four power collection lines (each one is connected to 10 transformers and 20 inverters) are connected to the bus bar in the power plant, and the bus bar is connected to the $35 \mathrm{kV}$ system through the $35 \mathrm{kV}$ outgoing line. Relevant parameters of the PV power plant are shown in Table 1.

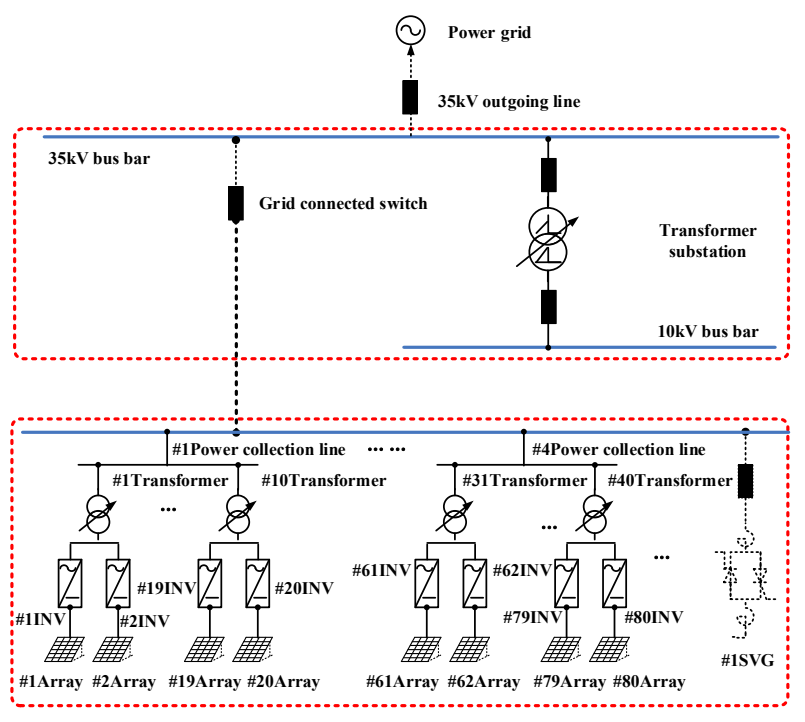

Fig. 6. System diagram of actual PV power plant.

Table 1. Relevant parameters of the PV power plant.

\begin{tabular}{|c|c|c|c|}
\hline \multicolumn{4}{|c|}{ PV inverters (*80) } \\
\hline $\begin{array}{c}\text { Rated active } \\
\text { power }\end{array}$ & $0.5 \mathrm{MW}$ & $\begin{array}{c}\text { Rated port } \\
\text { voltage }\end{array}$ & $0.315 \mathrm{kV}$ \\
\hline \multicolumn{4}{|c|}{ Transformers (*40) } \\
\hline $\begin{array}{c}\text { Low voltage } \\
\text { side }\end{array}$ & $0.315 \mathrm{kV}$ & $\begin{array}{c}\text { High voltage } \\
\text { side }\end{array}$ & $35 \mathrm{kV}$ \\
\hline Load loss & $11140 \mathrm{~W}$ & Load voltage & $6.29 \%$ \\
\hline No-load loss & $2.252 \mathrm{~kW}$ & No-load current & $0.3 \%$ \\
\hline \multicolumn{3}{|c|}{ Power collection lines (YJV-35KV/3*120) } \\
\hline \#1 line & $1150 \mathrm{~m}$ & \#2 line & $1250 \mathrm{~m}$ \\
\hline \#3 line & $1450 \mathrm{~m}$ & \#4 line & $2850 \mathrm{~m}$ \\
\hline
\end{tabular}

Next, the actual PV power plant would be modelled, analysed and calculated to verify the effectiveness of the control strategy proposed in this paper, so as to promote to more actual PV power plants. In this paper, the DIgSILENT/PowerFactory software was used to build a detailed model of the actual PV power plant according to the actual topology structure, the actual kind of the inverter and the actual parameters of the lines.

The example first verified the response performance of a single inverter to the voltage disturbance in the plant under the constant voltage control mode. By setting different constant voltage targets, the reactive power and voltage adjustment ability of the inverter under different active power output was verified respectively. Then, based on the actual operation data, the effectiveness of the control strategy proposed in this paper was verified when the active power changes within 24 hours. Finally, by setting the short circuit fault to make the system voltage suddenly change, the adaptive ability of the source-network coordination control strategy to resist the system voltage sudden change was studied.

\subsection{Verification of reactive power adjustment capacity of inverter}


When SVG and other reactive power compensation devices are in hot standby state, the inverter as the most important reactive power source in the plant needs to reserve sufficient adjustable reactive power capacity. In order to verify whether the PV inverter has good reactive power and voltage adjustment ability under the constant voltage operation mode, an actual operating inverter from the PV power plant was selected and the port target voltage was changed to respectively test the capacitive and inductive reactive power adjustment ability of the inverter under $100 \%$ output and $50 \%$ output conditions. The constant voltage target at the inverter outlet was set as 0.95p.u., 0.98p.u., 1.00p.u., 1.03p.u., 1.05p.u. and 1.08 p.u. to observe the reactive power output and actual port voltage of the inverter, as shown in Fig. 7.
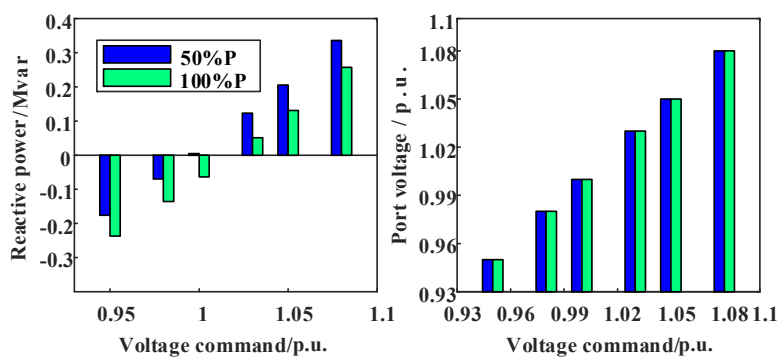

Fig. 7. Reactive power and voltage characteristics of inverter under constant voltage control.

Different active power will result in different port voltage level of inverter. In Fig. 7, the actual voltage response value of the inverter to the same target voltage is almost the same when the inverter operates under two different active power output conditions of $100 \%$ output and $50 \%$ output. It can be concluded that the inverter running in constant voltage control mode can automatically release capacitive reactive power and inductive reactive power according to the given voltage command value and adjust the bus voltage by using $Q-U$ characteristics to make it stable at the target voltage value. Therefore, as the reactive power source in the plant, the inverter can make full use of its reactive power adjustment ability to participate in the system voltage adjustment and achieve constant voltage control.

\subsection{Verification of reactive power and voltage control strategy of PV power plant}

In order to verify that the proposed coordination control strategy can effectively suppress the system voltage disturbance, dynamic simulation was carried out under the constant voltage control mode of PV inverter based on the actual operation data of PV power plant. Compared with the constant reactive power control method of PV inverter, this paper analyzed the adaptive coordination control ability of PV power plant and whether the control strategy proposed in this paper could enhance the PCC voltage stability. In addition, the adaptive ability of the proposed control strategy to resist voltage sudden change disturbance was verified by setting short-circuit fault.

\subsubsection{Adaptability to solar irradiance variation}

The 24-hour active power output of the actual PV power plant on July 11, 2018 (in Table 2) was selected as the calculation example data to verify the adaptability of the proposed control strategy to the transient disturbance under the condition of solar irradiance variation. According to the real-time output data, the proposed source-network coordination control strategy was used to calculate the command voltages of inverters (in Table 3) corresponding to each output and the voltages were substituted into the calculation example for simulation. The simulation results of reactive power output of each inverter and $35 \mathrm{kV}$ grid-connected bus voltage were shown as Fig. 8 and Fig. 9.

Table 2. 24-hour active output data of the PV power plant (unit: MW).

\begin{tabular}{|c|c|c|c|c|}
\hline Time & $\begin{array}{c}\text { Total } \\
\text { output of } \\
\text { \#1 line }\end{array}$ & $\begin{array}{c}\text { Total } \\
\text { output of } \\
\text { \#2 line }\end{array}$ & $\begin{array}{c}\text { Total } \\
\text { output of } \\
\text { \#3 line }\end{array}$ & $\begin{array}{c}\text { Total } \\
\text { output of } \\
\text { \#4 line }\end{array}$ \\
\hline $\mathbf{6 : 0 0}$ & 0 & 0 & 0 & 0 \\
\hline $\mathbf{7 : 0 0}$ & 1.78 & 1.73 & 1.79 & 1.76 \\
\hline $\mathbf{8 : 0 0}$ & 3.28 & 3.24 & 3.23 & 3.31 \\
\hline $\mathbf{9 : 0 0}$ & 5.35 & 5.28 & 5.37 & 5.32 \\
\hline $\mathbf{1 0 : 0 0}$ & 6.56 & 6.45 & 6.60 & 6.55 \\
\hline $\mathbf{1 1 : 0 0}$ & 6.40 & 7.03 & 6.19 & 7.50 \\
\hline $\mathbf{1 2 : 0 0}$ & 7.79 & 7.68 & 7.65 & 7.61 \\
\hline $\mathbf{1 3 : 0 0}$ & 6.14 & 4.36 & 5.41 & 6.34 \\
\hline $\mathbf{1 4 : 0 0}$ & 6.62 & 6.22 & 3.39 & 7.03 \\
\hline $\mathbf{1 5 : 0 0}$ & 5.76 & 5.45 & 5.74 & 2.87 \\
\hline $\mathbf{1 6 : 0 0}$ & 4.28 & 4.05 & 4.20 & 4.29 \\
\hline $\mathbf{1 7 : 0 0}$ & 1.95 & 1.05 & 2.20 & 1.30 \\
\hline $\mathbf{1 8 : 0 0}$ & 0 & 0 & 0 & 0 \\
\hline
\end{tabular}

Table 3. Command voltage value of PV inverters (unit: kV).

\begin{tabular}{|c|c|c|c|c|}
\hline Time & $\begin{array}{c}\text { Each } \\
\text { inverter } \\
\text { on \#1 line }\end{array}$ & $\begin{array}{c}\text { Each } \\
\text { inverter } \\
\text { on \#2 line }\end{array}$ & $\begin{array}{c}\text { Each } \\
\text { inverter } \\
\text { on \#3 line }\end{array}$ & $\begin{array}{c}\text { Each } \\
\text { inverter } \\
\text { on \#4 line }\end{array}$ \\
\hline $\mathbf{6 : 0 0}$ & 0.3150 & 0.3150 & 0.3150 & 0.3150 \\
\hline $7: 00$ & 0.3178 & 0.3178 & 0.3178 & 0.3180 \\
\hline $\mathbf{8 : 0 0}$ & 0.3206 & 0.3206 & 0.3206 & 0.3207 \\
\hline $\mathbf{9 : 0 0}$ & 0.3243 & 0.3243 & 0.3244 & 0.3244 \\
\hline $\mathbf{1 0 : 0 0}$ & 0.3265 & 0.3265 & 0.3265 & 0.3266 \\
\hline $\mathbf{1 1 : 0 0}$ & 0.3269 & 0.3270 & 0.3268 & 0.3270 \\
\hline $\mathbf{1 2 : 0 0}$ & 0.3288 & 0.3287 & 0.3288 & 0.3286 \\
\hline $\mathbf{1 3 : 0 0}$ & 0.3246 & 0.3245 & 0.3246 & 0.3246 \\
\hline $\mathbf{1 4 : 0 0}$ & 0.3252 & 0.3254 & 0.3249 & 0.3253 \\
\hline $\mathbf{1 5 : 0 0}$ & 0.3235 & 0.3235 & 0.3239 & 0.3228 \\
\hline $\mathbf{1 6 : 0 0}$ & 0.3221 & 0.3221 & 0.3221 & 0.3225 \\
\hline $\mathbf{1 7 : 0 0}$ & 0.3172 & 0.3170 & 0.3172 & 0.3168 \\
\hline $\mathbf{1 8 : 0 0}$ & 0.3150 & 0.3150 & 0.3150 & 0.3150 \\
\hline
\end{tabular}

It can be concluded that under the disturbance of solar irradiance variation on July 11 , the PCC voltage 
fluctuated greatly. Compared with the constant reactive power distribution method under the constant reactive power control mode, the source-network coordination control strategy proposed in this paper can effectively adjust the reactive power output of the inverter by using the constant voltage control mode according to the realtime solar irradiance variation, so as to realize the balanced control of the port voltage of each inverter. Finally, the daily voltage variation range of $35 \mathrm{kV}$ gridconnected bus was reduced from $2.846 \mathrm{kV}$ to $1.652 \mathrm{kV}$, down to $58 \%$ of the original, which enhanced the PCC voltage stability.

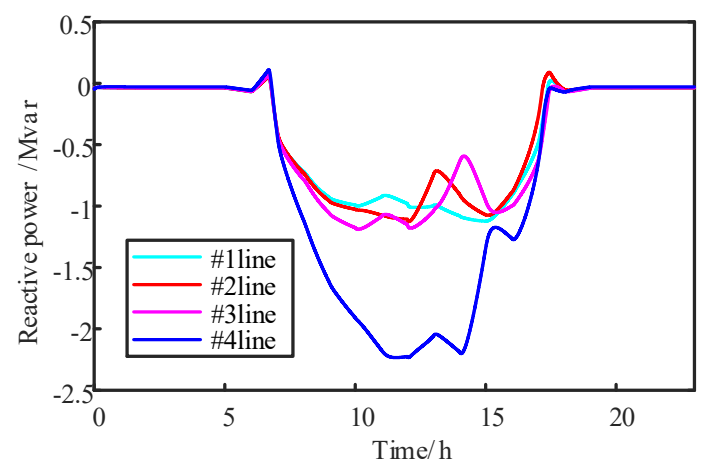

Fig. 8. Total reactive power output of inverters of each power collection line.

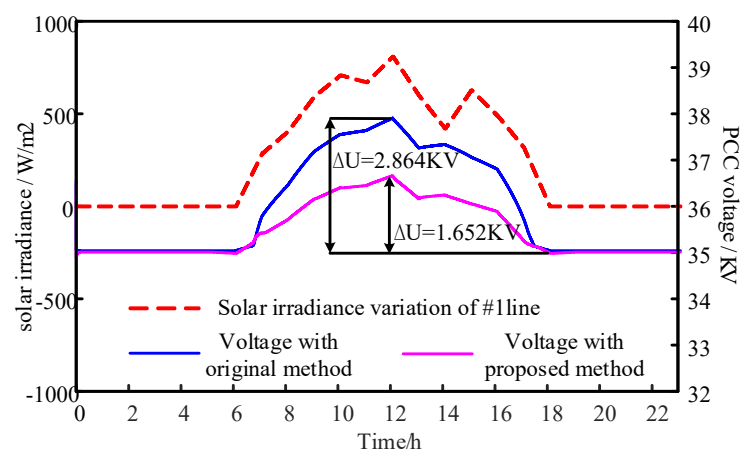

Fig. 9. The daily voltage variation range of $35 \mathrm{kV}$ gridconnected bus (July 11).

\subsubsection{Adaptability to voltage sudden change disturbance}

The system fault will cause PCC voltage to rise or fall randomly and the change of system power flow may also cause the bus voltage to fluctuate randomly. When the transient disturbance of system voltage sudden change occurs, the constant reactive power control mode cannot complete the fast response and voltage support to the voltage disturbance, and sometimes even further worsen the voltage disturbance. In order to verify the adaptability of the control strategy proposed in this paper to the voltage sudden change disturbance, the above-mentioned actual PV power plant was taken as the pilot and the three-phase short-circuit fault was set at PCC at $0.8 \mathrm{~s}$. The fault was cleared at $1.0 \mathrm{~s}$. During the fault process, the PCC voltage dropped to 0.6 p.u.. The reactive power of the inverters on \#1line and the PCC voltage change level were simulated as Fig. 10 and Fig. 11.

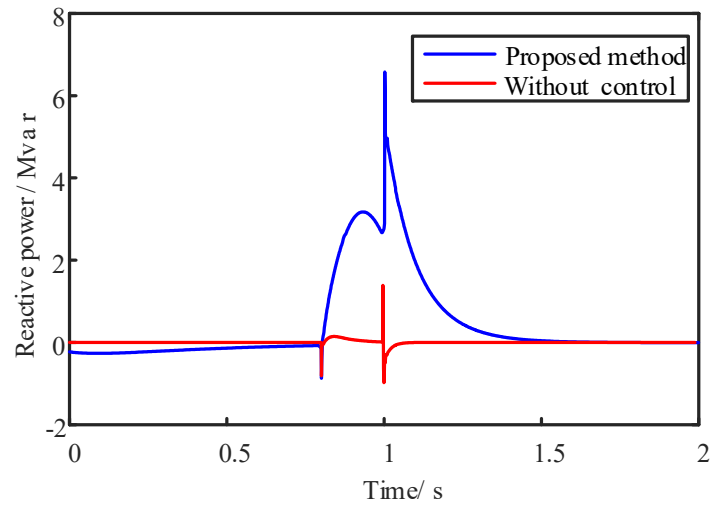

Fig. 10. The reactive power of the inverters on \#1line.

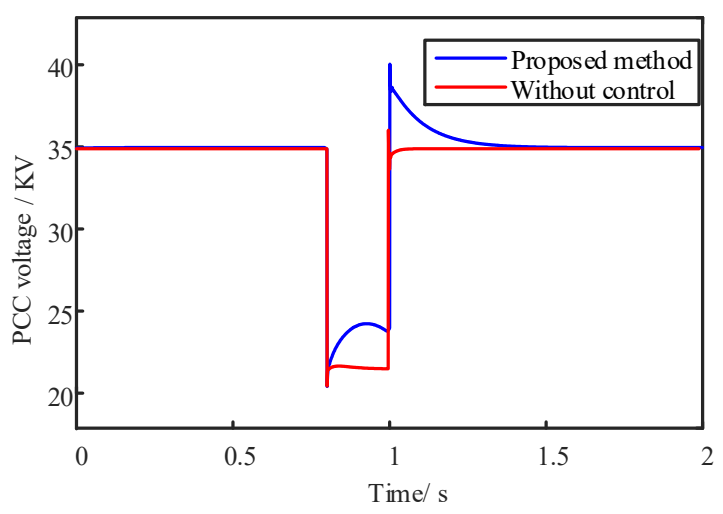

Fig. 11. The PCC voltage change level.

It can be concluded from the simulation that when the system occurs fault, compared with the PV power plant without reactive power and voltage control system, the control strategy proposed in this paper can be used to adjust the reactive power of the inverter and provide effective reactive power support for the system, so as to reduce the voltage drop and enhance the temporary voltage stability at PCC.

\section{Conclusion}

In view of the limitation of the current reactive power distribution method of the inverter in the PV power plant, this paper proposes a source-network coordination control strategy aiming at the stability of bus voltage at PCC and inverter port voltage. By building a simulation model of the actual PV power plant, it is verified that the proposed control strategy can effectively adapt to the two conditions of PV output fluctuation and system fault. When the system voltage is disturbed, the inverter can provide appropriate reactive power support according to the control strategy to realize the reactive power and voltage balance control between the inverters and the closed-loop voltage coordination control between the grid and PV power plant, which provide positive research results and theoretical guidance for the future widespread access of distributed power in the traditional power system. Next, the author will do further research on the following two points:

1) The first point is to seek the fast optimization algorithm of reactive power and voltage control in PV 
power plant to solve the reactive power and voltage coordination control scheme which can meet the requirements of reactive voltage adjustment cycle of PV inverter.

2) The second point is to study the multi-objective optimization and coordination control strategy to meet the requirements of voltage, loss, reactive power margin and gateway power factor, thus completing the distribution of reactive power and voltage command at PCC of PV power plant and enhancing the ability of source-network coordination control.

This paper is based on the Science and Technology Project of State Grid Anhui Electric Power Co., Ltd "Research on Key Technologies of New Energy Consumption and Coal-fired Unit Peak Load Regulation”.

\section{References}

1. S. Weckx, C. Gonzalez, and J. Driesen, "Combined central and local active and reactive power control of PV inverters," IEEE Trans. Sustain. Energy, vol. 5, no. 3, pp. 776-784, July (2014).

2. N. Mahmud and A. Zahedi, "Review of control strategies for voltage regulation of the smart distribution network with high penetration of renewable distributed generation," Renew. Sustain. Energy Rev., vol. 64, pp. 582-595, Oct. (2016).

3. H. Ge, R. Bi, Z. Xu, M. Ding, and K. Ren, "Research on reactive power and voltage control of large-scale photovoltaic power station," Power Syst. Prot. Control, vol. 42, no. 14, pp. 45-51, July (2014).

4. D. Novalio, D. Biswarup, and S. Jaydev, "Coordination between OLTC and SVC for voltage regulation in unbalanced distribution system distributed generation," IEEE Trans. Power Syst., vol. 29, no. 1, pp. 289-299, Jan. (2014).

5. S. Liu, J. Zhang, H. Wang, and S. Bai, "Two-stage reactive power and voltage coordinated control strategy for photovoltaic power station considering multiple reactive power sources," Autom. Electr. Power Syst., vol. 41, no. 11, pp. 120-125 and 168, June (2017).

6. X. Wang, Q. Guo, H. Sun, B. Wang, M. Zhang, and B. Zhang, "Secondary voltage control considering rapid dynamic reactive power compensation," Autom. Electr. Power Syst., vol. 39, no. 2, pp. 53-60, Jan. (2015).

7. J. Schiffer, T. Seel, J. Raisch, and T. Sezi, "Voltage stability and reactive power sharing in inverterbased microgrids with consensus-based distributed voltage control," IEEE Trans. Control Syst. Technol., vol. 24, no. 1, pp. 96-109, Jan. (2016).

8. E. Demirok, P. C. Gonzalez, KH. B. Frederiksen, D. Sera, P. Rodriguez, and R. Teodorescu, "Local reactive power control methods for overvoltage prevention of distributed solar inverters in low- voltage grids," IEEE J. Photovolt., vol. 1, no. 2, pp. 174-182, Oct. (2011).

9. K. Kouno, T. Sogabe, K. Itou, and M. Hojo, "Study on reactive power control of large-scale photovoltaic system for voltage regulation with long distribution line," 2015 IEEE Eindhoven PowerTech, Eindhoven, pp. 1-6, June (2015).

10. L. Zhou and N. Shao, "Reactive-power and voltage control for large-scale grid-connected photovoltaic plants," Electr. Power Autom. Equip., vol. 36, no. 4, pp. 116-122, April (2016).

11. T. Stetz, F. Marten, and M. Braun, "Improved low voltage grid-integration of photovoltaic systems in Germany," IEEE Trans. Sustain. Energy, vol. 4, no. 2, pp. 534-542, April (2013).

12. W. Moondee and W. Srirattanawichaikul, "Study of coordinated reactive power control for distribution grid voltage regulation with photovoltaic systems," 2019 IEEE PES GTD Grand International Conference and Exposition Asia (GTD Asia), Bangkok, Thailand, pp. 136-141, March (2019).

13. M. Ding, Z. Xu, W. Wang, X. Wang, Y. Song, and D. Chen, "A review on China's large-scale PV integration: Progress, challenges and recommendations," Renew. Sustain. Energy Rev., vol. 53, pp. 639-652, Jan. (2016).

14. S. Peng, H. Ma, L. Cao, L. Zhen, and J. Mao, "AVC system of renewable power station based on dynamic response parameters," Power Syst. Technol., vol. 43, no. 9, pp. 3328-3336, May (2019). 